Article

\title{
Online Grocery Shopping by NYC Public Housing Residents Using Supplemental Nutrition Assistance Program (SNAP) Benefits: A Service Ecosystems Perspective
}

\author{
Nevin Cohen ${ }^{1,2}, * \mathbb{C}$, Katherine Tomaino Fraser ${ }^{2}$, Chloe Arnow $^{3}$, Michelle Mulcahy ${ }^{3}$ and \\ Christophe Hille ${ }^{4}$ \\ 1 Department of Health Policy and Management, CUNY Graduate School of Public Health and Health Policy, \\ New York, NY 10027, USA \\ 2 CUNY Urban Food Policy Institute, New York, NY 10027, USA; Katherine.Tomaino@sph.cuny.edu \\ 3 Enterprise Community Partners, Inc., New York, NY 10004, USA; carnow@enterprisecommunity.org (C.A.); \\ mmulcahy@enterprisecommunity.org (M.M.) \\ 4 Karen Karp \& Partners, P.O. Box 515, Southold, NY 11971, USA; christophe@kkandp.com \\ * Correspondence: nevin.cohen@sph.cuny.edu; Tel.: +1-646-364-9605
}

Received: 6 May 2020; Accepted: 5 June 2020; Published: 9 June 2020

check for updates

\begin{abstract}
This paper examines adoption of online grocery shopping, and potential cost and time savings compared to brick and mortar food retailers, by New York City public housing residents using Supplemental Nutrition Assistance Program (SNAP) benefits. A mixed methods action research project involving the co-creation of an online shopping club, the Farragut Food Club (FFC), recruited 300 members who registered to shop online using SNAP, and received waivers on delivery minimums and provided technical assistance and centralized food delivery. We conducted a survey $(n=206)$ and focus groups to understand shopping practices; FFC members collected receipts of groceries over two weeks before and after the pilot to measure foods purchased, stores patronized, and prices. We interviewed FFC members to elicit experiences with the pilot, and estimated cost differences between products purchased in brick and mortar stores and equivalent products online, and transportation time and cost differences. Online shopping represented a small (2.4\%) percentage of grocery spending. Unit prices for products purchased on Amazon (\$0.28) were significantly higher than for equivalent products purchased in brick and mortar stores $(\$ 0.23)(p<0.001$.) Compatibility with existing routines, low relative advantage, and cost of online products limited the adoption of online shopping among SNAP users.
\end{abstract}

Keywords: Supplemental Nutrition Assistance Program (SNAP); food stamps; food access; online grocery shopping; innovation diffusion

\section{Introduction}

Online grocery shopping has grown over the past decade and uptake is likely to increase as retailers invest in distribution systems and consumers become accustomed to the practice [1-3]. An estimated $43 \%$ of Americans have purchased groceries online, $21 \%$ shop online for groceries monthly, and $10 \%$ once or more every two weeks [4,5]. One study predicts that $70 \%$ of US consumers will buy food and beverages online in 5-7 years [4]. Increased online shopping prompted by the COVID-19 pandemic may accelerate adoption. A key public health question is whether online grocery shopping improves food access for low-income consumers by reducing costs, saving time, increasing food availability, and enhancing convenience by eliminating shopping trips. 
Many low-income consumers have had limited access to online grocers because until recently, the US Department of Agriculture (USDA) prohibited online retailers from accepting Supplemental Nutrition Assistance Program (SNAP), putting online shopping out of reach for those who depend on the benefits [6]. To eliminate this disparity, the 2014 Farm Bill required USDA to pilot SNAP redemption at online grocers, and in response, the agency launched a pilot in New York in April 2019 with 3 food retailers: Amazon and ShopRite in New York City (NYC); and Walmart.com in the rest of New York State (NYS) [6-8]. In the wake of COVID-19, Amazon has since expanded its acceptance of SNAP to nine additional states (as of 5 May 2020: Alabama, Arizona, California, Florida, Iowa, Kentucky, Nebraska, Oregon, and Washington) and USDA has announced that online purchasing will be available in 36 states and the District of Columbia, covering more than $90 \%$ of SNAP participants nationwide [9].

Despite the USDA SNAP pilot and increasing numbers of SNAP participants now able to use their benefits online, only a few studies have examined adoption of online shopping among SNAP participants or low-income consumers more generally. One evaluation of a pilot by the online retailer Fresh Direct in NYC found that SNAP participants did not substantially shift their purchases from brick and mortar stores [10]. Focus groups with SNAP participants in the Southwest showed reluctance to shop online due to higher prices, challenging delivery logistics, and concerns about buying perishable food online [11]. Brandt et al. (2019) found that gaps in delivery services in rural areas prevented many SNAP participants from taking advantage of online ordering [12]. This paper adds to this limited literature by presenting the results of an 18-month action research project in which residents in a public housing development in Brooklyn, NY designed and implemented a project to facilitate online shopping among their neighbors.

The paper uses a service ecosystems framework to analyze the outcomes. This framework goes beyond diffusion of innovation theories that researchers have used to explain how new technologies and ideas spread as they are adopted [13]. Research on innovation diffusion has identified variables that speed or hamper adoption: relative advantage over the status quo; compatibility with pre-existing practices; the complexity of an innovation; trialability (whether adopters are locked into an innovation); and characteristics of early adopters or laggards [13]. Innovation diffusion literature has treated adopters as actors passively responding to innovations originating from businesses or governments, insufficiently considering the social dimensions of innovation, particularly the interconnected roles of innovators and consumers in creating and spreading innovations [14].

A service ecosystems perspective views innovation and diffusion as interconnected parts of the same process of co-creation [15]. Innovations are developed and spread as a result of producers and users co-designing solutions. Even a novel technology that emerges from a single firm requires multiple actors to establish new social norms and values that shape the innovation and affect how it is diffused [16]. Potential innovation users influence diffusion not only through their aggregated individual choices to adopt or reject them, but by influencing the social and institutional structures and material conditions that innovations need to spread and become embedded in everyday life [17]. Co-creation occurs through iterative feedback loops; as actors choose to use (or reject) innovations, they also provide creators with new ideas and solutions to technical problems and change the institutions that inhibit or facilitate the innovations. Positive feedback loops support innovations and spread them; negative feedback prevents institutional change and limits diffusion [18].

In a service ecosystem such as food retail, communities can develop new institutions that support the rapid adoption of an innovation such as online shopping, help to re-shape the innovation, contribute to institutional changes that reinforce older (i.e., brick and mortar) systems, or contribute to a new form of the innovation. Communities can also improve diffusion and adoption, while building their own power as consumers, by developing new institutions that help to expand market choice. This paper demonstrates how this process operates by presenting the results of an action research project in which residents of Farragut Houses, a New York City public housing development co-created an alternative food buying system that involved the use of online grocers and implemented a pilot test of 
this alternative. The paper analyzes the results of the pilot, adding to a growing body of literature on alternative food system innovations that have the potential to contribute to a more just, sustainable, and equitable food system.

\section{Methods}

This paper aims to provide comprehensive detail about the benefits of and obstacles to growing a culture of online food shopping using SNAP among public housing residents. It summarizes the process of organizing the FFC and reports the consensus of many conversations that led this group to design an alternative food buying system using online grocers. Action research involved working collaboratively with Farragut residents to analyze and address the problems they identified related to food access in their community, while also critically evaluating the process and outcomes [19-21]. The research steps, outlined below, included: Research site selection; recruitment of community collaborators; meeting facilitation to identify food access problems and potential solutions; co-design and implementation of a pilot intervention; and qualitative and quantitative evaluation of the intervention. The study methods outlined below were reviewed and approved by the CUNY Institutional Review Board.

\subsection{Research Team Formation}

Enterprise Community Partners, a national non-profit affordable housing organization, convened a team composed of: KK\&P, a food sector consultancy; Brooklyn Community Services (BCS), a non-profit community development organization; staff of the New York City Housing Authority (NYCHA) and the Fund for Public Housing; and researchers from the CUNY School of Public Health and Health Policy Urban Food Policy Institute.

\subsection{Site Selection}

The team identified Farragut Houses (Farragut), a NYCHA development in Brooklyn, as a project site based on several criteria: Similarity in size and population to other NYCHA developments; a functioning community center with supportive staff; a vibrant and active tenant association with organizing power; and no existing food access programming besides congregate meals for seniors. Farragut Houses has 1389 apartments with 3185 residents [22]. It is located in Vinegar Hill, a gentrifying neighborhood separated from more affluent communities by the Brooklyn and Manhattan Bridge off-ramps and a highway. Average annual household income is $\$ 22,420$, below federal and city poverty levels, with incomes of $47 \%$ of households under $\$ 15,000$. By comparison, median household income for the larger community district in which the development is located is $\$ 108,440$. About $50 \%$ of Farragut's residents are Black/African American, and 33\% are Hispanic or Latino/a.

Data on NYCHA residents overall indicate that a significantly higher percentage self-report their health status as fair or poor compared to New Yorkers not living in public housing. Other indicators of disparate dietary practices and health outcomes among this group include lower daily consumption of fruits and vegetables; higher consumption of sugary drinks; higher prevalence of overweight and obesity; and higher rates of high blood pressure [23].

At the start of the project, the only supermarket adjacent to Farragut was a small retailer called Fine Food. The Wegman's chain opened a large supermarket adjacent to the development in October 2019. Two other supermarkets are within a 15-min walk, and a 30-min walking boundary includes Target and 4 conventional supermarkets: Whole Foods, Stop \& Shop, Bravo, and Key Food.

\subsection{Recruitment of Community Collaborators}

To recruit community members within Farragut, the team posted flyers in the development's community center, made phone calls to targeted influencers identified by BCS, and held two recruitment meetings. Following these recruitment meetings, we identified a core group of interested residents (ranging, at times, between 6 and 20 individuals, with a consistent group of 4 core leaders.) This core group formed the Farragut Food Club (FFC) and met weekly between October 2018 and April 2019. 
Over the course of the project the FFC recruited and registered 220 Farragut residents to sign up for online food shopping using two food purchasing platforms: Amazon and Western Beef.

\subsection{Meeting Facilitation to Identify Food Access Problems and Potential Solutions}

The team supported the residents by facilitating weekly meetings and providing technical assistance as they discussed problems obtaining groceries, considered alternatives to existing food shopping methods, and designed an intervention to improve shopping opportunities. The team also provided nominal financial incentives to participants in the form of a $\$ 50$ gift card, with larger stipends (between $\$ 3000$ and $\$ 4000$ ) allocated to the group leaders.

\subsection{Co-Design of Pilot Intervention}

Over 6 months, the team and FFC co-designed a prototype to lower food access barriers that reflected data collected in the food environment scan, focus group, resident survey, and interviews. At each meeting, residents discussed concerns about existing food retail options, heard presentations from team members, discussed desired food retail alternatives, and considered the roles that the FFC might play in developing alternative food retail. The FFC aimed to address the limited number of affordable, high-quality grocers convenient to Farragut, and resident priorities for grocery shopping, including fair prices, wide selection, food quality, retailer reputation, and SNAP acceptance. Among other options, the FFC chose to partner with two online retailers: Amazon, which was scheduled to participate in the USDA SNAP online pilot, and Western Beef, a NY grocer that uses Instacart for online order fulfillment but is not in the USDA SNAP online pilot.

The FFC co-design process included facilitating ordering and delivery through Amazon and Western Beef. Online shopping was new to most FFC members, and even after the USDA pilot was launched, Farragut residents, like other low-income consumers, faced significant barriers to this shopping mode: Delivery fees and order minimums; buildings with restricted access for package delivery; unpredictable work hours that prevented scheduling deliveries; limited internet and computer access; inexperience with computers; and fear of the financial risks of lost deliveries or spoiled food. The co-design involved the FFC taking the following 10 steps to address some of these barriers:

1. Negotiating waivers of delivery minimums and monthly memberships;

2. Negotiating a mechanism for FFC member orders to be aggregated and delivered to the community center at the same time;

3. Creating secure storage infrastructure with refrigeration capacity by repairing a commercial-size refrigerator at the community center and purchasing a large, locked storage cage to store delivered parcels;

4. Organizing a service redelivering packages from the community center to homebound individuals, and coordinating flexible pick up of packages from the community center;

5. Providing computer access and technical support to residents unfamiliar with computers or online ordering;

6. Providing insights on bargains, deals, and affordable brands;

7. Promoting the FFC at tabling events and through emails to members;

8. Urging members to join weekly meetings to place orders with technical support on-hand;

9. Securing same-day delivery from Western Beef's warehouse; and

10. Establishing check-in calls with Amazon and Instacart project managers.

\subsection{Food Environment Scan}

CUNY conducted a food environment scan to analyze existing food retailers near the development, specifically resident access to supermarkets and other large food retailers. This involved mapping all food retail establishments in the vicinity of the development, using Arc-GIS and calculating 
15- and 30-min walking routes from the centroid of Farragut Houses to the food retailers within those boundaries.

\subsection{Farragut Resident Survey}

To understand shopping practices of Farragut residents prior to the pilot, CUNY surveyed a convenience sample of 206 Farragut residents between October 2018 and July 2019. Of those surveyed, 174 met screening criteria for inclusion: Being 18 years of age or older, residing at Farragut, and serving as primary food shopper in the household. The survey protocol was co-designed with project team members, pre-tested with public housing residents, and translated into Spanish. The survey questions elicited information about shopping frequency, grocery spending, time spent shopping, travel costs, and demographic information. Trained research assistants recruited from the Farragut community administered the survey, and CUNY researchers analyzed the survey data using Excel and SPSS to prepare descriptive statistics.

\subsection{Farragut Resident Focus Group}

To understand Farragut residents' needs, interests, and desires for improved access to groceries, CUNY convened a focus group of 6 Farragut residents who had begun to participate in weekly meetings of the Farragut Food Club. The focus group questions elicited information about the following: Shopping patterns, including where and when participants shop, time spent shopping for food to eat at home, perceptions of obstacles to buying healthy and affordable food, including issues of quality, value, access and convenience, logistics of grocery delivery, and desired alternatives to existing food retail options. Researchers recorded and transcribed the focus group discussion, then coded the responses for themes and frequency of themes, identifying and contextualizing representative quotes from focus group participants. Participants were offered a $\$ 20$ gift card as an incentive for their time.

\subsection{Pre-Pilot Grocery Receipt Analysis}

CUNY gathered data on food purchased to identify stores shopped in, specific items purchased, and the cost of those items in order to inform analysis of actual and potential economic savings of an alternative food buying system by FFC members. The team recruited and trained volunteers to collect receipts of all groceries they purchased during a 2-week period, and to manually record purchases that were made without receiving a receipt. All receipts were coded into a relational database that recorded the following: Receipt number; anonymized shopper code; store name; date and time of purchase; item of purchase; measurement unit; receipt price; quantity purchased; final price including discounts, taxes, bottle deposit fees; payment method; and images of the physical receipts. For receipts with product abbreviations/codes, CUNY conducted web searches for product information. For each item with weight/volume data, we calculated a unit price with and without store discounts. FFC members received $\$ 40$ gift cards for turning in two weeks' worth of receipts. Thirty-three (33) individuals provided grocery receipts from 330 shopping trips (2153 items) prior to the FFC pilot's launch in July 2019.

\subsection{Pilot Launch}

The FFC beta-launched its pilot to coincide with start of the USDA Online SNAP Pilot in April 2019, and fully launched the pilot in July 2019. Between July 2019 and January 2020, the FFC registered 300 residents with Amazon and 166 with Instacart/Western Beef.

\subsection{Post-Pilot Interviews with FFC Members}

The team recruited FFC members to participate in one-hour structured interviews to better understand member involvement with the FFC and their experiences purchasing food online, as well as their expectations for online and brick and mortar grocery shopping in the future. The interview 
protocol covered the following: Ease of access to desired food and grocery items; perceived benefits and disadvantages of online grocery shopping; logistics of participating in the FFC; logistics of ordering food online; and ideas for improvement of the project. CUNY researchers recorded and transcribed the interviews, and then coded the responses into themes, noting the frequency of themes among the interview transcripts. FFC members received $\$ 25$ gift-cards for participating in the interview. The results of the resident survey, focus group, and interviews helped the FFC design the pilot.

\subsection{Post-Pilot Receipt Analysis}

As described in Section 2.9, we repeated the process of receipt collection for 2-weeks' worth of grocery purchases to gather data on food purchased to identify stores shopped in, specific items purchased, and the cost of those items, in order to inform our analysis of actual and potential economic savings of an alternative food buying system by FFC members. Twenty individuals provided receipts from 110 shopping trips (655 items) during the post-pilot period.

\subsection{Post-Pilot FFC Member Survey}

To collect information of participant experiences with the SNAP Online Pilot and to elicit recommendations for improving grocery purchasing among NYCHA residents, we surveyed FFC members by recruiting from a contact list of 220 registered FFC members via email using Qualtrics survey software. Three follow-up reminders were sent.

\subsection{Post-Pilot Estimation of Grocery Cost Differences}

To estimate the potential cost savings of residents switching to online shopping from brick and mortar shopping, we compared brick and mortar purchases made by FFC members who collected grocery receipts pre- and post-pilot to equivalent products on Amazon.com. CUNY searched the Amazon catalogue for each item purchased in a brick and mortar store documented in FFC member receipts. Where the same brand purchased in the brick and mortar supermarket was not available on Amazon, we selected either the Whole Foods 365 brand (Amazon equivalent of a house brand) or the lowest-priced brand of the same type of product. We converted all prices to unit prices to enable comparisons by unit price. Non-parametric statistical tests (Mann-Whitney U test) were used to test the significance of differences in the distribution of brick and mortar and Amazon prices. Additionally, CUNY examined three market baskets representing actual purchases at Stop \& Shop, a favorite local supermarket, to equivalent products sold by Amazon and Western Beef.

\subsection{Post-Pilot Estimation of Online Grocery Shopping Time Savings}

To calculate the effects of adopting online shopping on transportation time, we calculated travel distances (using Google maps) from Farragut Houses to the stores that survey respondents reported patronizing, as well as to stores for which we received shopping receipts. Walking, public transit, and auto distances were calculated using shortest, average, and longest transit routes, distance, and time for each travel mode.

\subsection{Post-Pilot Estimation of Grocery Shopping Cost Savings}

To calculate the effects of adopting online shopping on cost savings, we estimated potential travel cost savings for online shopping by calculating the difference between total travel costs (i.e., fares and time value) by walking, transit, cars, and taxis, and a range of time $(15,30$, and $60 \mathrm{~min})$ residents reported in interviews and focus groups that they spent ordering groceries online and picking them up at the community center. To estimate the cost of car trips, we used the US General Services Administration per diem allocation of $\$ 0.57$ cents/mile for driving trips. For taxi rides, we used an online taxi fare calculator to estimate the price of the trip and added a $15 \%$ tip per trip. 
Out of pocket travel costs for each travel mode were calculated, and added to an economic value of travel time applying a US Department of Transportation method used for cost-benefit analysis of transportation projects [24] which assumes that the economic value of time spent traveling is equal to $50 \%$ of annual household income. The average hourly wage of a Farragut Houses resident, based on the average annual household income for all Farragut residents $(\$ 22,420)$ and a $40-\mathrm{h}$ workweek $(2080 \mathrm{~h}$ ) is $\$ 10.78 /$ hour, or approximately $\$ .18$ per minute. Using the DOT guidelines, we therefore assigned a value of $\$ .09 /$ minute for the time spent traveling to and from food retailers.

We calculated the total cost of travel as an individual's out of pocket costs for fares or travel expenses plus the time value for each mode of travel (i.e., fare + (roundtrip travel time * roundtrip time value $=$ total travel cost). Finally, we calculated the time value for online shopping durations of 15, 30, and $60 \mathrm{~min}$, the range of online shopping time residents indicated it takes them to place an order and pick up their packages at the Farragut Community Center. We calculated the percentage difference in time and time value between shopping online and taking different transportation modes to brick and mortar stores.

\subsection{Evaluation}

We evaluated the pilot using a mixed methods approach [25] to analyze residents' shopping practices, perceptions of online shopping, and grocery purchases prior to the start of the pilot, and both brick and mortar and online shopping practices after the pilot's launch. This outcome evaluation aimed to determine the extent to which residents changed their shopping practices when presented with an alternative food buying system, the uptake of online food shopping, and the potential cost and time savings to public housing residents.

\section{Results}

\subsection{Pre-Pilot Food Practices}

The majority of survey respondents reported spending more than $\$ 300$ on groceries monthly. Most respondents (89\%) buy groceries from supermarkets, including food retailers in the vicinity of Farragut plus more distant stores such as BJs, a club-format grocer more than 30-min by car from the development. Stop \& Shop, located a 25-min walk from the development, was the first, second, or third store preference of most respondents. BJs was the first or second choice of the second largest group of respondents.

Survey respondents typically grocery shop once or twice per month, with only $14 \%$ shopping weekly. Many residents time their shopping to coincide with monthly disbursement of SNAP funds. Most shopped at stores within walking distance or a combination of walking and bus. Approximately $30 \%$ reported spending more than $\$ 10$ to travel each way to shop for food.

\subsection{FFC Member Grocery Purchases}

A total of 53 FFC members submitted 2 weeks of grocery receipts (representing 440 unique shopping trips and 2808 items purchased between April 2018 and January 2020.) Individuals spent a median of $\$ 11.29$ on each purchase, reflecting that approximately $25 \%$ of shopping trips were for single items of $\$ 5.00$ or less, often at the adjacent Fine Food store. Stop \& Shop accounted for $32.6 \%$ of the value of all receipts, followed by Fine Food (12.1\%). Residents paid with a combination of SNAP, cash, and credit/debit cards.

Online purchases represented a small percentage of spending: $2.4 \%$ at Amazon and $0.7 \%$ at Western Beef. From the start of the pilot through Feb. 2020, 41 FFC members placed 209 orders on Amazon, an average of five orders/person over eight months. Fourteen FFC members placed 27 orders on Western Beef via Instacart. 


\subsection{Potential Time Savings Based on Self-Reported Shopping Time}

We did not track the shopping travel patterns of FFC members but estimated potential time savings based on survey respondents' self-reported shopping time and estimated travel time to the stores from which we received grocery receipts. Most survey respondents (59\%) reported spending $1-2 \mathrm{~h}$ to shop, including roundtrip travel and in-store time. Nearly one in five respondents $(19 \%)$ completed their shopping in less than one hour, while $18 \%$ reported taking more than two hours. By comparison, survey data indicate that residents who shopped online spent between 15 and $60 \mathrm{~min}$ to place an order online, with most reporting substantially quicker durations online than for conventional grocery shopping.

\subsection{Cost and Time Savings to Markets}

We measured the round-trip travel time to stores within a 30-min walking distance of the development and calculated that round trips were worth $\$ 0.54$ to $\$ 5.04$. For grocers beyond a 30-min walk, residents generally used either transit, a personal vehicle, or a taxi to get to and from the store. We calculated transit costs for those who qualify for half-fare Metrocards (\$2.75 roundtrip), and the time value for each trip. Total travel costs for paid travel ranged from approximately $\$ 5.45$ to $\$ 14.27$ per shopping trip. The driving costs, including both the value of time spent driving and the $\$ 0.57 \mathrm{cost} / \mathrm{mile}$ of car use, were less than $\$ 20$ roundtrip. Residents reported that they occasionally use taxis to go to and from supermarkets with trips ranging in total cost from approximately $\$ 30$ to nearly $\$ 100$.

The potential cost savings of substituting shopping online for brick and mortar trips ranged from a low of $\$ 0$, for online shopping in lieu of quick visits to nearby brick and mortar stores, to $\$ 14.85$ if a 15-min online order replaces a three-hour shopping trip.

\subsection{Price Differences between Brick and Mortar and Amazon}

We found that products on Amazon identified as equivalent to those purchased by residents in local stores were more frequently more expensive per unit price, as Figure 1 illustrates. We ran a Mann-Whitney $U$ test to determine the significance of the differences in unit prices between the two shopping modes. Distributions of the unit prices were statistically significantly higher online (median $=\$ 0.28$ ) than in brick and mortar stores (median $=\$ 0.23$ ), $\mathrm{U}=664,014, \mathrm{z}=-3.630, p<0.01$. This analysis indicates potential price differences between shopping modes, recognizing that the products on Amazon and brick and mortar stores were equivalent but not identical, and that attributes such as a store vs. brand name affect consumer appeal and price even if not product quality or function. In addition, prices were compared near the purchase date but can vary over time due to price promotions.

To assess the cost difference if someone switched entirely from shopping in a brick and mortar supermarket to shopping on Amazon, we compared three market baskets purchased by individuals at Stop and Shop, the brick and mortar supermarket frequented by most study participants, with Amazon equivalent items. In total, the Stop \& Shop purchases were approximately $10 \%$ to $26 \%$ cheaper than the equivalent market baskets on Amazon. The lower Stop \& Shop prices resulted primarily from price promotions or discounts, and without brick and mortar store discounts, Amazon would have been an average of $22.1 \%$ cheaper. 


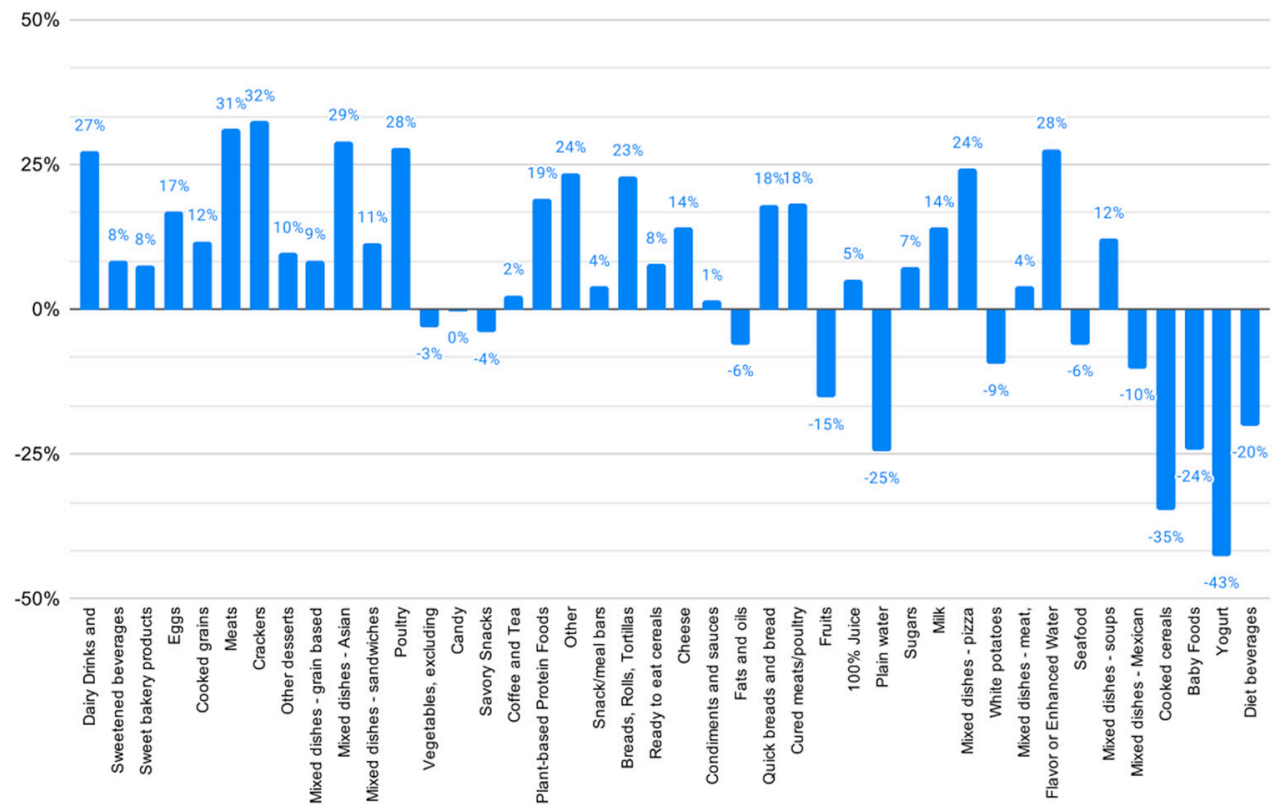

Figure 1. Product price differences for FFC members in \% between Amazon and brick and mortar stores, by major food category.

\subsection{Perceptions of Online Shopping by FFC Members}

FFC members described themselves in focus groups as closely attuned to sales and promotions at brick and mortar stores, searching for the best values, often through supermarket circulars and word of mouth. For interviewees, the most important shopping qualities were convenience and product value. Several interviewees felt that online shopping offered time savings and other conveniences. One said, "I like the fact that I have the choice with the [FFC] to have [Amazon] deliver or me go pick it up [from the community center]." Another explained, "[Online] was very convenient. I would do it again. It probably saved me about $4 \mathrm{~h}$ of going back and forth to the store." For some interviewees, the travel time to brick and mortar stores was significant. One explained, "The travel time is about ... 40 min because I have to take two buses." Another said, "I go to four stores each month...taking a full day and going to all four stores .... I usually take public transportation or borrow my sister's car if I can." Online ordering with home delivery was viewed as particularly convenient for heavy and bulky items, as one interviewee explained: "I still go to the store ... for small things. But if I'm going to need a lot, I'm going to use Instacart or Amazon. I buy [online] most of the heavy things .... ." Several interviewees said that having the community center as a pickup location made online ordering through FFC convenient. One explained, ".... I live across the street from where they deliver, so I can just go across the street, pick up my food."

Despite the advantages of online shopping noted by some respondents, several said that brick and mortar supermarket shopping fit their normal routines, suggesting that they would continue to shop at brick and mortar stores. As one explained: "If I had a list of what I wanted to get, and I wasn't able to get it from the store then it'd be better to order online. But sometimes I go into the store cause I'm just 'shopping for the day'." When asked about whether online shopping could replace brick and mortar shopping altogether, one person noted, "I would probably still shop in the stores. I am a creature of habit. I like to go to different stores to get deals. It would take me a long time before I would change my habits completely to shop online."

Online grocery shopping adds complexities to the existing routines of shopping. These include possible dissatisfaction with products purchased, the difficulty of returning unsatisfactory purchases, and concerns about delivery problems and losing money because a transaction was not made properly. 
One respondent feared identity theft: "I don't trust ordering online. That's how most people get their identity stolen ...." Several respondents had questions about the freshness of delivered foods. One said, "I would buy canned stuff [online], non-perishable things that I know aren't going to go bad ... . I don't want to order grapes, and they come wine." Another explained, "Shopping online is convenient. But I do like to go to the store and see what I'm getting, check the dates and things of that nature."

Technical issues with registration on Amazon inhibited use and made ordering difficult between the start of the USDA pilot until the end of June, possibly dissuading some FFC members from ordering after the pilot launched. Nonetheless, among those who ordered online, initial experiences were generally positive. One respondent said "delivery was very easy. [The packages] came when I expected ... and the quality of everything was good." Others described ordering as: "a good experience;" "very easy;" and "everything was packaged nicely: everything was cold that was supposed to be cold." When asked if their views of online grocery shopping changed during the pilot, participants said it was easier than they had thought. However, several respondents described initial attempts as experiments, not a full shopping experience.

The FFC members helped build trust in the online ordering and purchasing process by engaging in online shopping themselves and serving as models, and through explicit encouragement of others. The club's location in the development's community center, a space residents trust, may have also helped. One respondent said, "I don't trust [ordering online] generally, but I trust the people in the club, and I trust the computers here, so I am comfortable [ordering] this way."

Product value consists of variables like price and quality. Focus groups revealed that residents felt the value of the online options was good, though several respondents noted that online prices were often higher than for the same products sold in brick and mortar stores. One said, "[Amazon] quality was good but the price was expensive." When asked about the changes that would get them to shop online, one respondent said, "cheaper prices." When asked about the biggest barrier to grocery shopping online, the response was "probably the prices." Participants noted that they wished online stores such as Amazon had the same kinds of sales and circulars as brick and mortar supermarkets and mentioned the importance of senior discounts at local supermarkets. One participant explained, "[Supermarkets] have sales every week, 3 or 4 or 5 items are on sale, but you see the same prices on Amazon, and they never lower their prices." Most focus group participants and interviewees were satisfied with the quality of food purchased online. One explained: "I have an eye for meat, and the online [order] was not different than what I get in the store in terms of quality."

\section{Discussion}

A service ecosystems framework illustrates the important roles that the FFC played in co-creating an online grocery shopping system at Farragut. The FFC generated interest in the innovation of online grocery shopping as they co-designed and implemented the buying club and recruited community residents. The FFC also refined the innovation in several important respects: Negotiating free delivery without order minimums; organizing a package delivery and pick-up system at the community center to address concerns about delivery reliability and logistics; providing technical assistance to help novices learn how to use their computers to place orders; and creating a space for FFC members to meet and discuss their experiences. Their efforts led to institutional change, helping to normalize the practice of shopping for items online that are often considered unsuitable for sight-unseen purchases, like fresh fruits and vegetables and meat. Their co-creation efforts also altered the material conditions at Farragut, such as by opening up the community center to parcel delivery, redelivering packages to those with mobility limitations, and using the center's computer room to coach online shoppers. These were augmentations of the business models of Amazon and Instacart/Western Beef, illustrating that innovation adopters are not only individuals autonomously deciding whether and when to use an innovation, but are more actively engaged in re-shaping rules, norms, and material conditions, institutions that either block or facilitate innovations. If actively and directly engaged with during 
the roll out of an innovation, adopters can be critical catalysts for reshaping rules and norms of that innovation.

Notwithstanding the FFC's agency in the process, adoption of online shopping during the pilot remained modest among the Farragut residents, illustrating that the characteristics of innovations matter as well. The price difference between Amazon and brick and mortar stores was a major factor in whether and to what extent residents purchased online. Further, even inefficient practices can be resilient to change. Grocery shopping routines are reinforced through habit and the physical environment, and routines can be powerful barriers or facilitators of new modes of practice. Routines are often imposed on people by external factors, like an individual's work schedules, child- or parent-care responsibilities, or the frequency of SNAP benefit disbursement, which determine when, how frequently, and where people shop. Several interview respondents said that brick and mortar supermarket shopping fit their normal routines, or that their routines accommodated brick and mortar shopping.

As a single case study, the results explain and support theories of innovation adoption, but cannot be generalized to the larger population. Other limitations include: (1) The travel analysis assumed Farragut was the origin location for all shopping trips and attributed the travel to and from a store entirely to grocery shopping; (2) calculating time shopping as a cost undervalues benefits that some may get from traveling to a grocer, such as physical activity and social interaction, and overlooks inequities in labor market values that affect wage rates (and shadow prices); (3) calculating time shopping online also undervalues the flexibility it provides to families and the added value of time it frees up for other activities; (4) analysis did not explore the nuance of whether bulk purchases were made online and how that might influence store choice in the brick and mortar stores customers continue to shop at; and (5) the duration of study was too short to measure the longer-term impacts of co-creation on shopping patterns. The study ended prior to the COVID-19 pandemic, which has and will continue to affect in-person and online shopping patterns.

\section{Conclusions}

Farragut residents spend a significant portion of their income on groceries and prepare and eat meals at home most of the time. This means that improving the value and convenience of grocery shopping is likely to significantly affect their budgets and diets. Increasing food buying power and making a wider range of healthy food available has the potential to improve public housing residents' nutrition and reduce diet-related chronic health conditions. The SNAP online pilot has the potential to increase retail competition, provide access to more varied foods, and increase convenience by eliminating grocery trips. Furthermore, the pilot has the potential to create more resilience for public housing communities, as it equalizes and expands choice and access to online grocery sellers. During crises such as the COVID-19 pandemic and climate events, increased choice and access at this level may be an important tool to mitigating hunger and other related risks.

Our findings indicate that residents did not perceive a significant relative advantage for shopping online, largely due to more expensive prices on Amazon than for many equivalent products at brick and mortar stores. Coupons and store discounts accounted for much of the price differences between brick and mortar and online stores. Until online retailers are able to offer deals similar to the "supermarket circular," where many low-income individuals find discounts, it is likely that convenience of delivery will not overcome the cost differences.

Our action research project also illustrated the importance of innovation adopters in co-creating this new form of grocery shopping. At the start of the pilot, residents expressed reluctance to buy online for many of the same reasons market research firms have found nationwide. The FFC helped overcome some of these concerns and promoted adoption of online shopping by receiving, storing, and redistributing packages ordered online, helping with the mechanics of online shopping, and by sharing their positive experiences of purchasing online. Future policies to expand SNAP use online should programmatically and financially support peer-to-peer enterprises that positively influence the 
adoption of online shopping and that minimize barriers to entry experienced by many first-time online shoppers. These lessons can also be applied to other food and nutrition interventions by valuing and supporting the co-creation skills of those who are often viewed as mere passive adopters.

Author Contributions: Conceptualization and methodology, all; investigation, N.C., K.T.F.; writing-original draft preparation, N.C., K.T.F.; writing-review and editing, all; project administration, C.A., M.M.; funding acquisition, C.A., M.M., C.H., N.C. All authors have read and agreed to the published version of the manuscript.

Funding: This project received financial support from the Robin Hood Foundation and the Reinvestment Fund.

Acknowledgments: The authors would like to acknowledge all project partners who supported this work: Enterprise Community Partners, Karen Karp \& Partners, Brooklyn Community Services, the NYC Housing Authority, the Fund for Public Housing, and the Farragut Food Club, as well as all members of the Farragut Houses community.

Conflicts of Interest: The authors declare no conflicts of interest.

\section{References}

1. Coresight Research. US Online Grocery Survey 2019. Available online: https://coresight.com/research/usonline-grocery-survey-2019/ (accessed on 16 April 2020).

2. Business Insider. The Online Grocery Report: The Market, Drivers, Key Players, and Opportunities in a Rising Segment of Ecommerce. Available online: https://www.businessinsider.com/online-grocery-report-2020 (accessed on 16 April 2020).

3. Meena, S.; Swerdlow, F.; Kumar, S. The State of Global Online Grocery Retail; Forrester: Cambridge, MA, USA, 2018.

4. Nielsen and Food Marketing Institute. The Digitally Engaged Food Shopper: Developing Your Omnichannel Collaboration Model. Available online: https://www.fmi.org/digital-shopper (accessed on 21 February 2020).

5. Jones, J.M.; Kashanchi, S. Online Grocery Shopping Still Rare in U.S. Gallup. Available online: https: //news.gallup.com/poll/264857/online-grocery-shopping-rare.aspx (accessed on 20 February 2020).

6. United States Department of Agriculture. SNAP FNS Launches the Online Purchasing Pilot. Available online: https://www.fns.usda.gov/snap/online-purchasing-pilot (accessed on 15 April 2020).

7. United States Department of Agriculture. Healthful Foods Could Be Just a Click Away: FNS Works to Bring Online Shopping to Snap Purchases. Available online: https://www.usda.gov/media/blog/2016/08/ 02/healthful-foods-could-be-just-click-away-fns-works-bring-online-shopping-snap (accessed on 1 April 2020).

8. Cohen, N. SNAP at the Community Scale: How Neighborhood Characteristics Affect Participation and Food Access. Am. J. Public Health 2019, 109, 1646-1651. [CrossRef] [PubMed]

9. United States Department of Agriculture. SNAP Online Purchasing to Cover $90 \%$ of Households. Press Release No. 0268.20. 20 May 2020. Available online: https://www.fns.usda.gov/news-item/usda-026820 (accessed on 1 June 2020).

10. Martinez, O.; Tagliaferro, B.; Rodriguez, N.; Athens, J.; Abrams, C.; Elbel, B. EBT payment for online grocery orders: A mixed-methods study to understand its uptake among SNAP recipients and the barriers to and motivators for its use. J. Nutr. Educ. Behav. 2018, 50, 396-402. [CrossRef] [PubMed]

11. Rogus, S.; Guthrie, J.F.; Niculescu, M.; Mancino, L. Online Grocery Shopping Knowledge, Attitudes, and Behaviors Among SNAP Participants. J. Nutr. Educ. Behav. 2020, 52, 539-545. [CrossRef] [PubMed]

12. Brandt, E.J.; Silvestri, D.M.; Mande, J.R.; Holland, M.L.; Ross, J.S. Availability of Grocery Delivery to Food Deserts in States Participating in the Online Purchase Pilot. JAMA Netw. Open 2019, 2, e1916444. [CrossRef] [PubMed]

13. Rogers, E.M. Diffusion of Innovations, 4th ed.; The Free Press: New York, NY, USA, 1995.

14. Vargo, S.L.; Wieland, H.; Akaka, M.A. Innovation through institutionalization: A service ecosystems perspective. Ind. Mark. Manag. 2015, 44, 63-72. [CrossRef]

15. Vargo, S.L.; Akaka, M.A. Value Cocreation and Service Systems (Re)Formation: A Service Ecosystems View. Serv. Sci. 2012, 4, 207-217. [CrossRef]

16. Vargo, S.L.; Akaka, M.A.; Wieland, H. Rethinking the process of diffusion in innovation: A service-ecosystems and institutional perspective. J. Bus. Res. 2020. [CrossRef] 
17. Taillard, M.; Peters, L.D.; Pels, J.; Mele, C. The role of shared intentions in the emergence of service ecosystems. J. Bus. Res. 2016, 69, 2972-2980. [CrossRef]

18. Colyvas, J.A.; Jeannette, A. Ubiquity and legitimacy: Disentangling diffusion and institutionalization. Soc. Theory 2011, 29, 27-53. [CrossRef]

19. Lewin, G.W. (Ed.) Resolving Social Conflicts; Harper \& Row: New York, NY, USA, 1948.

20. Carter, G. Action research in community planning. J. Community Prac. 2003, 11, 121-131. [CrossRef]

21. Baum, F.; MacDougall, C.; Smith, D. Participatory action research. J. Epidemiol. Community Health 2006, 60, 854. [CrossRef] [PubMed]

22. US Department of Housing and Urban Development. Resident Characteristics Report. Available online: https://pic.hud.gov/pic/RCRPublic/rcrmain.asp (accessed on 30 November 2019).

23. New York City Department of Health and Mental Hygiene. Community Health Survey 2017. Available online: www1.nyc.gov/site/doh/data/data-sets/community-health-survey.page (accessed on 15 May 2019).

24. U.S. Department of Transportation. The Value of Travel Time Savings: Departmental Guidance for Conducting Economic Evaluations Revision 2 (2016 Update). Available online: https://www.transportation.gov/officepolicy/transportation-policy/revised-departmental-guidance-valuation-travel-time-economic (accessed on 16 April 2020).

25. Hesse-Biber, S. Qualitative Approaches to Mixed Methods Practice. Qual. Inc. 2010, 16, 455-468.

(C) 2020 by the authors. Licensee MDPI, Basel, Switzerland. This article is an open access article distributed under the terms and conditions of the Creative Commons Attribution (CC BY) license (http://creativecommons.org/licenses/by/4.0/). 